\title{
Article
}

\section{The effect of match fatigue in elite badminton players using plantar pressure measurements and the implications to injury mechanisms}

Valldecabres, Raul, Richards, James and de Benito, Ana-Maria Available at http://clok.uclan.ac.uk/31518/

Valldecabres, Raul, Richards, James ORCID: 0000-0002-4004-3115 and de Benito, Ana-Maria (2020) The effect of match fatigue in elite badminton players using plantar pressure measurements and the implications to injury mechanisms. Sports Biomechanics . ISSN 1476-3141

It is advisable to refer to the publisher's version if you intend to cite from the work. http://dx.doi.org/10.1080/14763141.2020.1712469

For more information about UCLan's research in this area go to http://www.uclan.ac.uk/researchgroups/ and search for <name of research Group>.

For information about Research generally at UCLan please go to http://www.uclan.ac.uk/research/

All outputs in CLoK are protected by Intellectual Property Rights law, including Copyright law. Copyright, IPR and Moral Rights for the works on this site are retained by the individual authors and/or other copyright owners. Terms and conditions for use of this material are defined in the policies page. 
1 Main title: The effect of match fatigue in elite badminton players using

2 plantar pressure measurements and the implications to injury

3 mechanisms

4

5 Running title: The effect of match fatigue in elite badminton players

6

7 Raúl Valldecabres ${ }^{1,2}$ (orcid.org/0000-0002-7478-7526)

8 Jim Richards ${ }^{3}$ (orcid.org/0000-0002-4004-3115

9 Ana-María de Benito² (orcid.org/0000-0002-8836-4073)

10

11

$12{ }^{1}$ Doctorate School, Valencia Catholic University San Vicente Mártir. Valencia, Spain.

$13{ }^{2}$ Physical Activity and Sports Science Faculty, Valencia Catholic University San Vicente 14 Mártir. Valencia, Spain.

$15{ }^{3}$ Allied Health Research Unit, University of Central Lancashire, Preston, United 16 Kingdom.

17

18 Corresponding author:

19 Raúl Valldecabres

20 raul.valldecabres@ucv.es

21 


\section{Main title: The effect of match fatigue in elite badminton players using \\ 23 plantar pressure measurements and the implications to injury mechanisms}

25

\section{Running title: The effect of match fatigue in elite badminton players}

27

Word count: 7557

Abstract

The purpose of this study was to investigate the differences in plantar pressure under the lead and trail foot between two lunge tasks to the net in the dominant (LD) and nondominant (LND) directions, and to explore how fatigue affects the plantar pressure patterns whilst performing movements before and after a competitive match. Peak and mean pressure were measured with the Biofoot-IBV in-shoe system from five repetitions of each task, with sensors positioned under the calcaneus, midfoot and phalanges on the lead and trail foot. Data were collected pre and immediately post playing an official 1st national league competition match. The study was conducted with a sample of thirteen 1 st league badminton players. A $2 \times 2$ repeated ANOVA found significant differences between the two tasks and between pre and post match (fatigued state). Players also had different foot pressure distributions for the LD and LND tasks, which indicated a difference in loading strategy. In a fatigued state the plantar pressure shifted to the medial aspect of the midfoot in the trail limb, indicating a reduction in control and a higher injury risk during non-dominant lunge tasks.

Abstract word count: 172 


\section{Introduction}

Badminton is reported to be the fastest racket sport when considering ball velocity (Jaitner $\&$ Gawin, 2007). Its popularity has grown since its inclusion at the '92 Olympic Games in Spain and the use of a new scoring system in 2006 (Chen, Wu, \& Chen, 2011), with up to 200 million players worldwide (Kwan, Cheng, Tang, \& Rasmussen, 2010). The sport is characterised by short duration high intensity actions placing a high demand on the anaerobic system (Cabello \& González-Badillo, 2003). The sport requires good footwork including; rapid turning, pivoting, jumps, lunges and running; in order for players to reach and hit the shuttlecock and to return to a defensive position in the centre of the court (Gibbs, 1988) which has not been analysed previously. There is a lack of quantification the court movements on the literature in a real competition context.

It has previously been reported that up to $70 \%$ of injuries are to the lower limbs, with the remaining 30\% being due to loss of balance, slips and falls, landing or collisions with other players (Hensley \& Paup, 1979; Krøner et al., 1990; Reeves, Hume, Gianotti, Wilson, \& Ikeda, 2015). However, as in other racquet and field sports, badminton cannot be appropriately simulated in the laboratory setting (Faude et al., 2007). The majority of match based studies on badminton performance have focussed on notational performance analysis (Abián, Castanedo, Feng, Sampedro, \& Abián-Vicén, 2014; Barreira, Chiminazzo, \& Fernandes, 2016), game characteristics (Phomsoupha \& Laffaye, 2014), or physiological and ground reaction force data (Chen et al., 2011; Ramos, Del Castillo, Polo, Ramón, \& Bosch, 2016).

Players footwork during lunge movements has been previously reported (Kuntze, Mansfield, \& Sellers, 2010), however the nature of on court movements had not been considered until recently (Valldecabres, de Benito, Casal, \& Pablos, 2017). Valldecabres et al. (2017) divided the court into 12 parts, and described 3 different on court footwork movements which were commonly used to hit the shuttle, these were; diagonal, transverse and longitudinal, of which more than 50\% were diagonal court movements.

Several studies have investigated injuries during badminton (Hensley \& Paup, 1979; Jørgensen \& Winge, 1990), with a higher risk of injury during competitions when compared to training sessions (Jørgensen \& Winge, 1990). Of these injuries, 43\% have 
been reported as patellar tendinopathy (Shariff, George, \& Ramlan, 2009), which is considered a common injury in sports with jumps, cutting manoeuvres and explosive running tasks (Tibesku \& Pässler, 2005). The clinical injury risk incidence has also been analysed and found that $26 \%$ of players had previous symptoms before getting injured (Fahlström, Björnstig, \& Lorentzon, 1998) being overuse sprains and strains the most musculoskeletal common injury (Goh, Mokhtar, \& Mohaman, 2013; Hensley \& Paup, 1979; Shariff, George, \& Ramlan, 2009). Lower limb dominance is an important consideration during sports tasks, and has been identified as a factor associated with potential Anterior Cruciate Ligament injury risk (Negrete, Schick, \& Cooper, 2007). However, lower limb dominance seems to be more related to specific movement tasks which require different side to side movements (Peters, 1988), such as one side being used for more postural stabilization (Velotta, Weyer, Ramirez, \& Winstead, 2011). This was highlighted by Sinsurin, Vachalathiti, Srisangboriboon \& Richards (2018) who found better coordination during multi-direction jump landings on the non-dominant limb. The literature also suggests differences in the injury incidence between the dominant and nondominant limbs for many sports, which has been attributed to side to side differences in loading as a result of differences in movement strategies between the sides (Vauhnik et al., 2008). For example, Kimura et al. (2010) reported that the knee on the lead limb side was the most commonly injured in badminton players, in particular during cutting and side-step movements to the racket-hand side. In addition, Krajnc et al. (2010) showed that the non-dominant leg, defined as the one that is not used to kick a ball, suffered more knee injuries than the dominant leg in soccer players, with players requiring more operations with greater pain or discomfort after surgery on the non-dominant limb. Side to side differences have also been identified in badminton (Kimura et al., 2010), with a higher number of injuries seen on the non-dominant leg.

The incidence of lower limb injuries has also been shown to be linked to fatigue, which has been associated with a decrease in neuromuscular control, impaired kinesthesis and proprioception of joints, and a diminishing maximum voluntary strength (Dickin \& Doan, 2008; Rozzi, Yuktanandana, \& Pincivero, 2000; Saragiotto, Di Pierro, \& Lopes, 2014; Whyte, Burke, White, \& Moran, 2015). Links between fatigue and exercise have been investigated previously, however the exact definition of fatigue varies between studies (López-Calbet \& Dorado-García, 2006). Fatigue may be considered as multidimensional or multifactorial (Hunter \& Smith, 2007; Millet et al., 2011), which may be characterised 
118 by the decrease of the capacity or ability to generate force or muscle power. This originates from physiological, mechanical and psychological modifications (Stirling, Von

120 Tscharner, Fletcher, \& Nigg, 2012) and a reduction of performance, which has been described as a conservative response to maintain tissue integrity (Millet et al., 2011).

122 Previous work considering fatigue in badminton players has shown that dynamic postural

123 control and the quality of athletes' performance is lower in a post fatigue state (Sarshin,

124 Mohammadi, Shahrabad, \& Sedighi, 2011). Players' perceived fatigue may be assessed

125 using the rating of perceived exertion scale (Borg, 1982a), which has been shown to be 126 valid for the assessment of exercise intensity during badminton matches (Fernández, de la Aleja, Moya, Cabello, \& Méndez, 2013).

Previous investigations into sports related tasks have shown plantar pressure is an important method of quantifying the magnitude and location of the force applied beneath the foot, which may be measured using in shoe pressure systems (Falda-Buscaiot, Hintzy, Rougier, Lacouture, \& Coulmy, 2017; Navarro, Zahonero, Huertas, Vera, \& Barrios, 2012). Fu, Liu \& Wei (2009) studied badminton lunge tasks, and found the maximum peak pressure was distributed under the forefoot with lower pressures under the midfoot. Conversely, Hu, Li, Hong \& Wang (2015) found lower pressures under the forefoot with the maximum pressure under the heel, indicating either differences in movement strategy or test protocol. Changes in distribution of foot pressure, for example midfoot loading, has been associated with foot pronation and patellofemoral pain (Thijs, Van Tiggelen, Roosen, De Clercq, \& Witvrouw, 2007; Powers, 2003). In addition, the static assessment of foot posture using the Foot Posture Index (Redmond, Crosbie, \& Ouvrier, 2006) has been shown to be important in the prediction of clinical subgroups in people with patellofemoral pain (Selfe et al., 2016). Therefore, the use of foot pressure may allow an assessment of changes in loading strategy and dynamic postural control on the trail and lead limbs which could be performed in the competition arena. This could be useful in the assessment of training and injury prevention, or when considering when to return to sport after an injury.

The aims of the present study were to investigate the differences in plantar pressure under the trail and lead foot between two lunge tasks to the net, and to explore how fatigue affects the plantar pressure patterns whilst performing movements before and after a competitive match. It was hypothesised that lunge tasks to the dominant side (LD) and 
152 lunge tasks to the non-dominant side (LND) would show different foot loading strategies

153 and that players would show changes in plantar pressure patterns in a fatigue state.

\section{Methods}

\section{Participants}

156 The inclusion criteria for both genders were; players in the $1^{\text {st }}$ Spanish badminton league

157 who played at least 3 times a week, with no injuries to the upper and lower limbs in the

158 previous 6 months. In addition, all participants had no history of surgery or traumatic

159 injury to the lower extremities or lower back, and no history of medical conditions that

160 limit physical activity. Exclusion criteria included; presence of neuromuscular or vestibular conditions, visual impairment or back pain.

162

163 Thirteen right-handed badminton players ( 5 males and 8 females) participated in the study. Anthropometric measurements of height and weight were recorded; age $25.93 \pm$ 10.05 years and bodyweight $64.30 \pm 8.66 \mathrm{~kg}$. Hand laterality was assess using a previously validated questionnaire (Chapman \& Chapman, 1987), which includes questions such as which hand do you use to throw a ball or which foot do you use to kick a ball, which has been used in previous studies (Brophy, Silvers, Gonzales, \& Mandelbaum, 2010; English, Brannock, Chik, Eastwood, \& Uhl, 2006). In addition, Foot Posture Index (FPI), a clinical tool that measures foot type between +12 (pronated) and 12 (supinated) was recorded (Redmond, Crosbie, \& Ouvrier, 2006). This study was approved by the Valencia Catholic University San Vicente Mártir Ethics Committee and all data collection conformed to the Declaration of Helsinki. Volunteers gave written informed consent and parental consent for the four participants who were minors was obtained prior to participation.

\section{Equipment}

178 In shoe plantar pressure data were recorded using the Biofoot-IBV in-shoe system 179 (Valencia, Spain), which consists of 64 sensors of $0.5 \mathrm{~mm}$ thickness and $5 \mathrm{~mm}$ diameter 180 and has been previously validated and used to assess sports tasks (Martínez, Hoyos, 181 Brizuela, Ferrús, \& González, 1988; Marhuenda, Fuentes, Costa, Ferrús, \& González, 182 2011). Not normalised peak and mean pressure data were used according to previous 
studies (Patrick, \& Donovan, 2018; Taylor, Nguyen, Griffin, \& Ford, 2018). In addition, the regions of interest where normalised to foot size following Oliveira, Sousa, Santos, \& Tavares (2012) with values for foot shape proposed by Hu et al. (2015).

\section{Procedure}

In order to familiarise the players, submaximal lunge tasks were performed to the right and left sides, LD and LND respectively for a right-handed player (figure 1). During the lunge, the role of the non-stepping limb is to support the bodyweight during the forward movement of the lead limb (Hofmann, Holyoak, \& Juris, 2017) and reaches a maximum knee flexion during landing, this is followed by a movement backwards in order to recover to the initial starting position (Kuntze et al., 2010). The lunge tasks were performed at $45^{\circ}$ to the net in the defensive position (Gibbs, 1988), and were defined as controlled movements of the knee such that the knee did not move in front of the ankle joint. The most natural start position for the lunge task was identified for each player in order to hit a shuttlecock that was hung using a fine thread at a height of $165 \mathrm{~cm}, 10 \mathrm{~cm}$ from the net (figure 2). Prior to data collection, a standardised 10 minute warm-up was performed, which included active stretching of the quadriceps and hamstring muscles (Lam et al., 2017), specifically this involved five repetitions of 30 seconds per muscle; and a familiarization period which involved the participants performing as many repetitions of the lunge tasks as they needed to feel comfortable (Gribble, Hertel, \& Plisky, 2012).

[Figures 1 and 2 near here]

Pressure sensors were then placed in both shoes by fixing them to the insole to avoid them moving within the shoe. Changes in foot pressure data were recorded at a sampling frequency of $265 \mathrm{~Hz}$. en directions. Each lunge task trial consisted of a lunge to the net, hitting the shuttlecock with a top-spin shot and moving back to the start position as fast as possible to simulate a match shot. Approximately 5 minutes after participants had played a competition match the lunge tests were repeated. In addition, the level of match intensity was assessed using the Rated Perceived Exertion (RPE) Scale (Borg, 1982a). This determined the perceived intensity of the exercise, from 0 (nothing at all) to 10 (very, very heavy) (Borg, 1982b). 
217 The plantar surface of the foot was divided into 9 areas previously reported by Navarro

218 et al. (2012) (figure 3), these included; hallux, $2^{\text {nd }}$ and $3^{\text {rd }}$ phalanges and $4^{\text {th }}$ and $5^{\text {th }}$ 219 phalanges, $1^{\text {st }}$ metatarsal, $2^{\text {nd }}$ and $3^{\text {rd }}$ metatarsals and $4^{\text {th }}$ and $5^{\text {th }}$ metatarsals, medial 220 midfoot and lateral midfoot, and calcaneus. The peak pressure (PP) and average pressure 221 (PMEAN) of the whole foot were recorded and an average value from 5 repetitions was 222 found for each parameter for each movement direction for both the lead and trail feet.

224 [Figure 3 near here]

\section{Statistical Analysis}

227

228 Based on previous papers by Lam et al. (2017) and Park et al. (2017) and an alpha level 229 of 0.05 and an $80 \%$ power, a sample size of at least 13 was found to be required to explore 230 the differences between sides and fatigue state. The data were checked for normality using 231 the Shapiro-Wilk test and found to be suitable for parametric testing. In addition, partial 232 eta squared $\left(\eta p^{2}\right)$ was computed to determine the effect size which was interpreted as 233 small 0.1, medium 0.3, and large 0.5. Statistical analysis was performed with SPSS 21.0 234 (IBM, Armonk, NT, USA).

A 2x2 repeated ANOVA found significant differences between the two tasks and between pre and post match (fatigued state).

\section{Results}

239 The players had a mean RPE after playing the competition match of 7.54 (SD 2.10), with 240 a range of perception of fatigue between strong and extremely strong. The average match 241 length was 26 minutes 29 seconds with a standard deviation of 8 minutes and 9 seconds. 242 The FPI showed mean values of 1.17 (SD 1.79) for the lead foot and 1.50 (SD 1.72) for 243 the trail foot, which corresponds to a neutral foot posture (Redmond, Crosbie, \& Ouvrier, 244 2006). All players were at a similar level, and were all Spanish $1^{\text {st }}$ league competitors and were playing for the Championship. 
247 Significant main effects were seen between pre and post fatigue on the lead foot. These revealed significant differences under the 4th and 5th Phalangeal areas between pre and post fatigue for the peak and mean pressure $\left(p=0.035, \eta p^{2}=0.32 ; p=0.031, \eta p^{2}=0.33\right.$ ) respectively, with lower values in a fatigue state. In addition, a reduction of lead foot peak pressure under the lateral side was seen with a corresponding increase in peak pressure under the medial side of the midfoot, although the latter was not statistically significant (table 1). A significant interaction was seen between the factors of lunge task and fatigue state under the $2 \mathrm{nd}$ and 3rd Metatarsals $\left(\mathrm{p}=0.011, \eta \mathrm{p}^{2}=0.43\right)$. Further post hoc analysis explored differences between pre and post fatigue for each lunge task separately, which showed an increase in peak pressure post fatigue for the LD task and a decrease with the LND task (table 1). In addition, the calcaneus mean pressure for the lead foot in the LD task was lower than the LND task $\left(p=0.032, \eta p^{2}=0.33\right)($ Table 2$)$, indicating a different strategy during landing between lunge tasks.

[Tables 1 and 2 near here]

Significant differences were also seen under the 1st Metatarsal on the trail foot pre and post fatigue for the peak and mean pressure $\left(p=0.048, \eta p^{2}=0.29 ; p=0.046, \eta p^{2}=0.29\right)$ respectively, with a decrease in pressure post fatigue in both LD and LND tasks, and a corresponding significant increase in medial midfoot pressure. Finally, the medial midfoot showed an increase in peak and mean pressure post fatigue for both the LD and LND tasks ( $\left.p=0.022, \eta p^{2}=0.37 ; p=0.046, \eta p^{2}=0.29\right)$ respectively (Tables 3 and 4$)$, which would imply a shift in pressure to the medial midfoot as the players fatigue.

Significant main effects were seen between LD and LND tasks. These revealed differences in the peak and mean pressure under the Hallux $\left(p=0.008, \eta p^{2}=0.45 ; p=0.020\right.$, $\eta p^{2}=0.38$ ) respectively. This showed the Hallux pressure was lower in the LND task than the LD task in the trail foot (tables 3 and 4), with a corresponding lower pressure in the LND task versus the LD task for the peak and mean pressure under the 4th and 5th Phalangeal areas $\left(p=0.026, \eta p^{2}=0.35 ; p=0.017, \eta p^{2}=0.39\right)$ respectively (tables 3 and 4$)$. In addition, significant differences were found between the LD and LND tasks in the mean pressure under the Hallux $\left(\mathrm{p}=0.038, \eta \mathrm{p}^{2}=0.31\right)$ (table 4). Furthermore, a significant interaction was also seen for the peak pressure under the 2nd and 3rd Phalangeal areas in 
280 the trail foot between lunge task and fatigue state $\left(\mathrm{p}=0.017, \eta \mathrm{p}^{2}=0.39\right)$, with a greater pressure being seen during the LD task, although this was not significant (Table 3). A

282

[Tables 3 and 4 near here] further post hoc analysis revealed a significant difference in peak pressure between pre and post fatigue in the LD task on the trail foot only ( $\mathrm{p}=0.045, \eta \mathrm{p}^{2}=0.30$ ).

\section{Discussion and Implications}

A fatigue state has been shown to reduce athletes' performance and can lead to poor joint control (Chang, 2015) and a decrease in dynamic postural control in badminton players (Sarshin et al., 2011). Furthermore, the biomechanics and movement patterns have been shown to be modified as a result of fatigue (Chang, 2015), which could lead to a subsequent increase in injury rate. Footwork manoeuvres are therefore extremely important for badminton players and the consideration of how landing strategies change on the different limbs after fatigue may help us to understand injury mechanisms (Phomsoupha \& Laffaye, 2014). Diagonal lunge tasks have been previously shown to account for approximately $50 \%$ of on court manoeuvres in both male and female players (Valldecabres et al., 2017). This movement is required to allow the players to move to hit the shuttlecock, and the speed and reaction time are important to allow the player to recover a defensive court position to be ready for the next shot (Gibbs, 1988). Therefore, the aim of this study was to explore differences in foot contact pressures under the lead and trail foot during two badminton specific lunge tasks to the net, and to determine how plantar pressure patterns change as the players' fatigue.

The Foot Posture Index has been used to determine foot type in athletes in different sports including; basketball, handball and running (Martínez-Nova et al., 2014). Our results show a neutral foot type across the participants. However, when athletes fatigue, their foot posture tends to move towards a more pronated position (Cowley \& Marsden, 2013), which could be an indicator of arch collapse leading to an increase of plantar pressure under the medial midfoot. Jørgensen \& Winge (1990) reported that more than $30 \%$ of lower limb injuries are to the foot or ankle joint. This could be related to a flattening of the arch with a more pronated foot position (Lange, Chipchase, \& Evans, 2004), leading to associated injuries (Barton, Bonanno, Levinger, \& Menz, 2010; Beeson, Phillips, Corr, 
313 \& Ribbans, 2009; Graham, Jawrani, \& Goel, 2011; Raissi, Cherati, Mansoori, \& Razi, 314 2009).

316 This study found an increase in pressure under the medial aspect of the lead foot, 317 indicating a more pronated foot or a collapse of the arch post fatigue with the adoption of 318 a flatter foot posture, which is in line with previous findings (Wei, Liu, Tian, \& Fu, 2009).

319 This would arguably increase the pronation and pronation velocity which have been 320 previously identified as key factors in patellofemoral pain and patellar tendinopathy in runners (Powers, 2003; Thijs et al., 2007), the latter of which has been identified as an issue in $43 \%$ of badminton players (Shariff et al., 2009). In addition, the side-to-side differences found may help to explain the higher injury rates which have been reported on the non-dominant leg (Krajnc et al., 2010). One consideration to help mitigate this effect is the use of foot orthoses. These could be used to directly manage foot posture by supporting the arch and therefore decreasing the pronation and pronation velocity when athletes are in a fatigued state. This in turn may reduce the incidence of patellar tendinopathy (Mündermann, Nigg, Humble, \& Stefanyshyn, 2003). However, more research is needed to explore the use of foot orthotics in badminton players, and their effect on potential injury mechanisms when athletes are in a fatigued state.

When comparing LD and LND tasks on lead foot, there are differences in pressure under the Hallux, a lower pressure under the 4th and 5th Phalangeal areas and a lower calcaneus mean pressure, which indicates a possible change in strategy during landing as Vauhnik et al. (2008) reported in other court sports. Lower pressure on the forefoot and lateral areas could be due to the involvement of pelvic rotation which has been reported by players who find dominant side movements easier than non-dominant side ones (Bazipoor, Shojaeddin, Shahhoseini, \& Abdollahi, 2017). Further exploration of such compensations was beyond the scope of this current study

After fatigue, a significant decrease in mean pressure under the Hallux and 1st Metatarsal areas and a significant increase under medial midfoot were seen in both LD and LND tasks. This would support the shift in pressure to the medial midfoot and collapse of the arch when players reach a fatigued state which is in agreement with previous literature (Weist, Eils, \& Rosenbaum, 2004), and supports that changes in plantar pressure distribution occur due to fatigue (Bisiaux \& Moretto, 2008). This has implications to the 
347 foot movement used to recover the initial position in the centre of the court with cutting 348 and pivoting creating a higher tibia rotation torque (Oh, Kreinbrink, Wojtys, \& Ashton349 Miller, 2012) which has been linked with patella mal-alignment and an increased risk of patellofemoral pain (Sinclair \& Dillon, 2016).

351

352 During both LND and LD lunge tasks the Hallux, 4th and 5th Metatarsals all showed 353 lower mean and peak pressure on the trail limb (tables 3 and 4). The explanation for this 354 could be different hip movement strategies when lunging towards the net, with movement into hip external rotation during the LD task, and a move into hip internal rotation when performing the LND task which has been previously reported by Valldecabres, de Benito, Littler \& Richards (2018). In addition, the trail limb is in contact with the ground for longer and is responsible for the eccentric control as the person lunges forwards, which is similar to findings reported during fencing, where the trail/rear limb demonstrated lower pressures (Trautmann, Martinelli, \& Rosenbaum, 2011).

This current study is the first to explore the plantar pressure patterns in the lead and trail foot. Previously published work by $\mathrm{Hu}$ et al. (2015) on plantar pressures during badminton movements has only taken into account the dominant/lead limb during lunge tasks to the net. This work offers a contribution to knowledge on the changes in movement strategies due to fatigue within a competition environment in elite players. However, more work is required to assess how fatigue affects pronation and pronation velocity, knee joint stability and compensations in pelvic rotation in badminton players.

371 This study was not without its limitations which included a large standard deviation in 372 the age of the players recruited. A large standard deviation was seen in many of the 373 parameters reported, this was due to variations in the magnitude of many of the 374 parameters between the participants, however the direction of the changes seen were 375 common among the participants which accounts for the significant differences seen, and supports the conclusion that a change in strategy occurs due to fatigue. In addition, no 377 direct measures of the amount of pronation or pronation velocity were taken. 378 Furthermore, greater fatigue has been previously reported as a competition progresses, 379 however this current study did not report how many matches were played at the time of 
assessment, although the match duration was similar to that reported by Abián-Vicén,

381 Castanedo, Abián, \& Sampedro (2013).

382

\section{Conclusion}

384 In conclusion, this study found that players have different strategies when moving to the 385 dominant and non-dominant sides during lunge to the net tasks. Under a fatigue state the 386 plantar pressure shifts to the medial aspect of the midfoot in the trail limb indicating a 387 reduction in control of the midfoot and collapse of the arch. This could account for the 388 higher injury risk in the non-dominant trail limb which has been previously reported in 389 badminton players, therefore further work should consider both the lead and trail foot. 390 These results provide new insights into the changes in foot function in a fatigued state, 391 which could possibly be managed using foot orthoses.

\section{Disclosure statement}

394 There is no conflict of interest reported by authors.

395

\section{$396 \quad$ Funding details}

397 This study has been made possible by Generalitat Valenciana ACIF 121/2015 grants for 398 PhD students and Valencia Catholic University San Vicente Mártir grant to new research 399 groups.

400

\section{Acknowledgments}

402 We would like to thank Badminton Spanish Federation for support and access to the real 403 competition context and Club Bádminton Alicante for allowing us a court in sports centre. 404 Data collection was possible thanks to (in alphabetical order): Omar Aguar, Carlos 405 Baeschlin, Joaquín Barrachina, Yvan Barthelemy, Claudio Alberto Casal, Diego Ceca, 406 Raúl Fernández, Encarnación Liébana and Cristina Menescardi. 
Abián, P., Castanedo, A., Feng, X. Q., Sampedro, J., \& Abián-Vicén, J. (2014). Notational comparison of men's singles badminton matches between Olympic Games in Beijing and London. International Journal of Performance Analysis in Sport, 14(1), 42-53. doi:10.1080/24748668.2014.11868701

Abián-Vicén, J., Castanedo, A., Abián, P., \& Sampedro, J. (2013). Temporal and notational comparison of badminton matches between men's singles and women's singles. International Journal of Performance Analysis in Sport, 13(2), 310-320. doi:10.1080/24748668.2013.11868650

Barreira, J., Chiminazzo, J. G. C., \& Fernandes, P. T. (2016). Analysis of point difference established by winners and losers in games of badminton. International Journal of Performance Analysis in Sport, 16(2), 687-694. doi:10.1080/24748668.2016.11868916

Barton, C. J., Bonanno, D., Levinger, P., \& Menz, H. B. (2010). Foot and ankle characteristics in patellofemoral pain syndrome: A case control and reliability study. Journal of Orthopaedic \& Sports Physical Therapy, 40(5), 286-296. doi:10.2519/jospt.2010.3227

Bazipoor, P., Shojaeddin, S. S., Shahhoseini, A., \& Abdollahi, I. (2017). A comparison of foot plantar pressure in badminton players with normal and high-arched feet during the two-way lunge. Journal of Rehabilitation Sciences and Research, 1, 20-25. doi:10.30476/JRSR.2017.41114

Beeson, P., Phillips, C., Corr, S., \& Ribbans, W. J. (2009). Hallux rigidus: A crosssectional study to evaluate clinical parameters. The Foot, 19(2), 80-92. doi:10.1016/j.foot.2008.12.001

Bisiaux, M., \& Moretto, P. (2008). The effects of fatigue on plantar pressure distribution in walking. Gait \& Posture, 28(4), 693-698. doi:10.1016/j.gaitpost.2008.05.009 
Borg, G. (1982a). A category scale with ratio properties for intermodal and interindividual comparisons. In: Geissler HG, Petzold P, eds. Psychophysical Judgment and the Process of Perception, 25-34.

Borg, G. (1982b). Psychophysical bases of perceived exertion. Medicine and Science in Sports Exercice, 15(5), 377-381. doi:10.1249/00005768-198205000-00012

Brophy, R., Silvers, H. J., Gonzales, T., \& Mandelbaum, B. R. (2010). Gender influences: the role of leg dominance in ACL injury among soccer players. British Journal of Sports Medicine, 44(10), 694-697. doi:10.1136/bjsm.2008.051243

Cabello, D., \& González-Badillo, J. J. (2003). Analysis of the characteristics of competitive badminton. British Journal of Sports Medicine, 37(1), 62-66. doi:10.1136/bjsm.37.1.62

Chang, C. (2015). Research on the biomechanics analysis of technical movement in fatigue period for badminton athletes. International Journal of Simulation Systems, $\quad$ Science \& Technology, 16(4B), 13.1-13.6. doi:10.5013/IJSSST.a.16.4B.13

Chapman, L. J., \& Chapman, J. P. (1987). The measurement of handedness. Brain and Cognition, 6(2), 175-183. doi:10.1016/0278-2626(87)90118-7

Chen, H. L., Wu, C. J., \& Chen, T. C. (2011). Physiological and notational comparison of new and old scoring systems of singles matches in men's badminton. Asian Journal of Physical Education \& Recreation, 17(1).

Cowley, E., \& Marsden, J. (2013). The effects of prolonged running on foot posture: a repeated measures study of half marathon runners using the foot posture index and navicular height. Journal of Foot and Ankle Research, 6(1), 1-6. doi:10.1186/1757-1146-6-20

Dickin, D. C., \& Doan, J. B. (2008). Postural stability in altered and unaltered sensory 
environments following fatiguing exercise of lower extremity joints: Postural control following fatiguing exercise of lower extremity joints. Scandinavian Journal of Medicine \& Science in Sports, 18(6), 765-772. doi:10.1111/j.16000838.2007.00760.x

English, R., Brannock, M., Chik, W. T., Eastwood, L. S., \& Uhl, T. (2006). The relationship between lower extremity isokinetic work and single-leg functional hop-work test. Journal of Sport Rehabilitation, 15(2), 95-104. doi:10.1123/jsr.15.2.95

Fahlström, M., Yeap, J. S., Alfredson, H., \& Söderman, K. (2006). Shoulder pain-a common problem in world-class badminton players. Scandinavian Journal of Medicine \& Science in Sports, 16(3), 168-173. doi:10.1111/j.16000838.2004.00427.x

Falda-Buscaiot, T., Hintzy, F., Rougier, P., Lacouture, P., \& Coulmy, N. (2017). Influence of slope steepness, foot position and turn phase on plantar pressure distribution during giant slalom alpine ski racing. PLoS One, 12(5), e0176975. doi:10.1371/journal.pone.0176975

Faude, O., Meyer, T., Rosenberger, F., Fries, M., Huber, G., \& Kindermann, W. (2007). Physiological characteristics of badminton match play. European Journal of Applied Physiology, 100(4), 479-485. doi:10.1007/s00421-007-0441-8

Fernández, J., de la Aleja, J. G., Moya, M., Cabello, D., \& Méndez, A. (2013). Gender differences in game responses during badminton match play: Journal of Strength and Conditioning 27(9), Research, 2396-2404. doi:10.1519/JSC.0b013e31827fcc6a

Fu, W. J., Liu, Y., \& Wei, Y. (2009). The characteristics of plantar pressure in typical footwork of badminton. Footwear Science, I(sup1), 113-115. 
Gibbs, M. J. (1988). Badminton-Teaching concepts. Journal of Physical Education, Recreation \& Dance, 59(8), 92-94. doi:10.1080/07303084.1988.10606299

487

488

489

490

491

492

493

494

495

496

497

498

499

500

501

502

503

504

505

506

507

508

Graham, M. E., Jawrani, N. T., \& Goel, V. K. (2011). Evaluating plantar fascia strain in hyperpronating cadaveric feet following an extra-osseous talotarsal stabilization procedure. The Journal of Foot and Ankle Surgery, 50(6), 682-686. doi:10.1053/j.jfas.2011.07.005

Gribble, P. A., Hertel, J., \& Plisky, P. (2012). Using the star excursion balance test to assess dynamic postural-control deficits and outcomes in lower extremity injury: A literature and systematic review. Journal of Athletic Training, 47(3), 339-357. doi:10.4085/1062-6050-47.3.08

Hensley, L. D., \& Paup, D. C. (1979). A survey of badminton injuries. British Journal of Sports Medicine, 13(4), 156-160. doi:10.1136/bjsm.13.4.156

Hofmann, C. L., Holyoak, D. T., \& Juris, P. M. (2017). Trunk and shank position influences patellofemoral joint stress of the lead and trail limb during the forward lunge exercise. Journal of Orthopaedic \& Sports Physical Therapy, 47(1), 31-40. doi:10.2519/jospt.2017.6336

Hu, X., Li, J. X., Hong, Y., \& Wang, L. (2015). Characteristics of plantar loads in maximum forward lunge tasks in badminton. PLoS One, 10(9), e0137558. doi:10.1371/journal.pone.0137558

Hunter, I., \& Smith, G. A. (2007). Preferred and optimal stride frequency, stiffness and economy: changes with fatigue during a 1-h high-intensity run. European Journal of Applied Physiology, 100(6), 653-661. doi:10.1007/s00421-007-0456-1

Jaitner, T., \& Gawin, W. (2007). Analysis of badminton smash with a mobile measure device based on accelerometry. In ISBS-Conference Proceedings Archive (Vol. 
510 Jørgensen, U., \& Winge, S. (1990). Injuries in badminton. Sports Medicine, 10(1), 5964. doi:10.2165/00007256-199010010-00006

Kimura, Y., Ishibashi, Y., Tsuda, E., Yamamoto, Y., Tsukada, H., \& Toh, S. (2010). Mechanisms for anterior cruciate ligament injuries in badminton. British Journal of Sports Medicine, 44(15), 1124-1127. doi:10.1136/bjsm.2010.074153

Krajnc, Z., Vogrin, M., Rečnik, G., Crnjac, A., Drobnič, M., \& Antolič, V. (2010). Increased risk of knee injuries and osteoarthritis in the non-dominant leg of former professional football players. Wiener Klinische Wochenschrift, 122(S2), 40-43. doi:10.1007/s00508-010-1341-1

Krøner, K., Schmidt, S. A., Nielsen, A. B., Yde, J., Jakobsen, B. W., Møller-Madsen, B., \& Jensen, J. (1990). Badminton injuries. British Journal of Sports Medicine, 24(3), 169-172. doi:10.1136/bjsm.24.3.169

Kuntze, G., Mansfield, N., \& Sellers, W. (2010). A biomechanical analysis of common lunge tasks in badminton. Journal of Sports Sciences, 28(2), 183-191. doi:10.1080/02640410903428533

Kwan, M., Cheng, C. L., Tang, W. T., \& Rasmussen, J. (2010). Measurement of 526 badminton racket deflection during a stroke. Sports Engineering, 12(3), 143-153. doi:10.1007/s12283-010-0040-5 shoe heel design influence ground reaction forces and knee moments during maximum lunges in elite and intermediate badminton players? PloS one, 12(3), e0174604. doi:10.1371/journal.pone.0174604 
Lange, B., Chipchase, L., \& Evans, A. (2004). The effect of low-dye taping on plantar pressures, during gait, in subjects with navicular drop exceeding $10 \mathrm{~mm}$. Research Report, 34(4), 9. doi:10.2519/jospt.2004.34.4.201

López Calbet, J., \& Dorado Garcia, C. (2006). Fatiga, dolor muscular tardío y sobreentrenamiento. López Chicharro, J. y Fernández Vaquero, A. Fisiologia del ejercicio. $3^{a}$ edición. Madrid: Edtiorial Médica Panamericana.

Marhuenda, A. M., Fuentes, J. V. H., Costa, G. B., Ferrús, E., \& González, J. C. (2011). Biofoot-IBV. Una técnica de registro y análisis de la distribución de presiones plantares aplicable a la mejora del rendimiento deportivo. Colección ICD: Investigación en Ciencias del Deporte, 19.

Martínez, A., Hoyos, J. V., Brizuela, G., Ferrús, E., \& González, J. C. (1988). BiofootIBV. Una técnica de registro y análisis de la distribución de presiones plantares aplicable a la mejora del rendimiento deportivo. Colección ICD: Investigación en Ciencias del Deporte, 19, 73-88.

Martínez-Nova, A., Gómez-Blázquez, E., Escamilla-Martínez, E., Pérez-Soriano, P., Gijon-Nogueron, G., \& Fernández-Seguín, L. M. (2014). The foot posture index in men practicing three sports different in their biomechanical gestures. Journal of the American Podiatric Medical Association, 104(2), 154-158. doi:10.7547/0003-0538-104.2.154

Millet, G. Y., Banfi, J. C., Kerherve, H., Morin, J. B., Vincent, L., Estrade, C., Geyssant, A. \& Feasson, L. (2011). Physiological and biological factors associated with a $24 \mathrm{~h}$ treadmill ultra-marathon performance: Factors associated with ultramarathon performance. Scandinavian Journal of Medicine \& Science in Sports, 21(1), 54-61. doi:10.1111/j.1600-0838.2009.01001.x

Mündermann, A., Nigg, B. M., Humble, R. N., \& Stefanyshyn, D. J. (2003). Foot 

orthotics affect lower extremity kinematics and kinetics during running. Clinical Biomechanics, 18(3), 254-262. doi:10.1016/S0268-0033(02)00186-9

Navarro, D., Zahonero, J., Huertas, F., Vera, P., \& Barrios, C. (2012). Efecto de las plantillas podológicas de acomodación selectiva en la presión plantar de ciclistas profesionales. Estudio Preliminar. Presented at I Simposio sobre Biomecánica y pie durante la Actividad Física, Santander.

Oh, Y. K., Kreinbrink, J. L., Wojtys, E. M., \& Ashton-Miller, J. A. (2012). Effect of axial tibial torque direction on ACL relative strain and strain rate in an in vitro simulated pivot landing. Journal of Orthopaedic Research, 30(4), 528-534. doi:10.1002/jor.21572

Oliveira, F. P. M., Sousa, A., Santos, R., \& Tavares, J. M. R. S. (2012). Towards an efficient and robust foot classification from pedobarographic images. Computer Methods in Biomechanics and Biomedical Engineering, 15(11), 1181-1188. doi:10.1080/10255842.2011.581239

Park, S. K., Lam, W. K., Yoon, S., Lee, K. K., \& Ryu, J. (2017). Effects of forefoot bending stiffness of badminton shoes on agility, comfort perception and lower leg kinematics during typical badminton movements. Sports Biomechanics, 16(3), 374-386. doi:10.1080/14763141.2017.1321037

Patrick, K., \& Donovan, L. (2018). Test-retest reliability of the Tekscan ${ }^{\circledR}$ F-Scan ${ }^{\circledR} 7$ inshoe plantar pressure system during treadmill walking in healthy recreationally active individuals. Sports Biomechanics, 17(1), 83-97. doi:10.1080/14763141.2017.1355010

Peters, M. (1988). Footedness: Asymmetries in foot preference and skill and neuropsychological assessment of foot movement. Psychological Bulletin, 103(2), 179-192. doi:10.1037/0033-2909.103.2.179 
600

601

602

603

604

605

606

Phomsoupha, M., \& Laffaye, G. (2014). The Science of badminton: game characteristics, anthropometry, visual fitness and biomechanics. Sports Medicine, 11, 1-45. doi:10.1007/s40279-014-0287-2

Powers, C. M. (2003). The influence of altered lower-extremity kinematics on patellofemoral joint dysfunction: a theoretical perspective. Journal of Orthopaedic \& Sports Physical Therapy, 33(11), 639-646. doi:10.2519/jospt.2003.33.11.639

Raissi, G. R. D., Cherati, A. D. S., Mansoori, K. D., \& Razi, M. D. (2009). The relationship between lower extremity alignment and Medial Tibial Stress Syndrome among non-professional athletes. BMC Sports Science, Medicine and Rehabilitation, 1(1). doi:10.1186/1758-2555-1-11

Ramos, J. J., Del Castillo, M. J., Polo, C., Ramón, M., \& Bosch, A. (2016). Analysis of the physiological parameters of young Spanish badminton players. Revista Internacional de Medicina y Ciencias de la Actividad Física y del Deporte, 16(61), 45-54. doi:10.15366/rimcafd2016.61.004

Redmond, A. C., Crosbie, J., \& Ouvrier, R. A. (2006). Development and validation of a novel rating system for scoring standing foot posture: The foot posture index. Clinical Biomechanics, 21(1), 89-98. doi:10.1016/j.clinbiomech.2005.08.002

Reeves, J., Hume, P., Gianotti, S., Wilson, B., \& Ikeda, E. (2015). A retrospective review from 2006 to 2011 of lower extremity injuries in badminton in New Zealand. Sports, 3(2), 77-86. doi:10.3390/sports3020077

Rozzi, S., Yuktanandana, P., \& Pincivero, D. (2000). Role of fatigue on proprioception and neuromuscular control. In S. Lephart \& F. Fu (Eds.), Proprioception and Neuromuscular Control Joint Stability (pp. 375-383). Champaign, IL: Human Kinetics. 
607

608

609

610

611

612

613

614

615

616

617

618

619

620

621

622

623

624

625

626

627

628

629

630

631

Saragiotto, B. T., Di Pierro, C., \& Lopes, A. D. (2014). Risk factors and injury prevention in elite athletes: a descriptive study of the opinions of physical therapists, doctors and trainers. Brazilian Journal of Physical Therapy, 18(2), 137-143. doi:10.1590/S1413-35552012005000147

Sarshin, A., Mohammadi, S., Shahrabad, H. B. P., \& Sedighi, M. (2011). The effects of functional fatigue on dynamic postural control of badminton players. Biology of Exercise, 7(2), 25-34. doi:10.4127/jbe.2011.0047

Selfe, J., Janssen, J., Callaghan, M., Witvrouw, E., Sutton, C., Richards, J., Stokes, M.,Martin, D., Dixon, J., Hogarth, R., Baltzopoulos, V., Ritchie, E.,Arden, N., \& Dey, P. (2016). Are there three main subgroups within the patellofemoral pain population? A detailed characterisation study of 127 patients to help develop targeted intervention (TIPPs). British Journal of Sports Medicine, 50(14), 873880. doi:10.1136/bjsports-2015-094792

Shariff, A. H., George, J., \& Ramlan, A. A. (2009). Musculoskeletal injuries among Malaysian badminton players. Singapore Medical Journal, 50(11), 1095.

Sinclair, J., \& Dillon, S. (2016). Influence of run and cut manoeuvres on patellofemoral kinetics and kinematics. British Journal of Sports Medicine, 50(22), e4.14-e4. doi:10.1136/bjsports-2016-096952.21

Sinsurin, K., Vachalathiti, R., Srisangboriboon, S., \& Richards, J. (2018). Knee joint coordination during single-leg landing in different directions. Sports Biomechanics, 1-13. doi:10.1080/14763141.2018.1510024

Stirling, L. M., Von Tscharner, V., Fletcher, J. R., \& Nigg, B. M. (2012). Quantification of the manifestations of fatigue during treadmill running. European Journal of Sport Science, 12(5), 418-424. doi:10.1080/17461391.2011.568632

Taylor, J. B., Nguyen, A.-D., Griffin, J. R., \& Ford, K. R. (2018). Effects of turf and cleat 

footwear on plantar load distributions in adolescent American football players during resisted pushing. Sports Biomechanics, 17(2), 227-237. doi:10.1080/14763141.2016.1271448

Thijs, Y., Van Tiggelen, D., Roosen, P., De Clercq, D., \& Witvrouw, E. (2007). A prospective study on gait-related intrinsic risk factors for patellofemoral pain. Clinical Journal of Sport Medicine, 17(6), 437-445. doi:10.1097/JSM.0b013e31815ac44f

Tibesku, C., \& Pässler, H. (2005). Jumper’s knee. Sportverletzung Sportschaden, 19(02), 63-71. doi:10.1055/s-2005-858141

Trautmann, C., Martinelli, N., \& Rosenbaum, D. (2011). Foot loading characteristics during three fencing-specific movements. Journal of Sports Sciences, 29(15), 1585-1592. doi:10.1080/02640414.2011.605458

Valldecabres, R., de Benito, A. M., Littler, G., \& Richards, J. (2018). An exploration of the effect of proprioceptive knee bracing on biomechanics during a badminton lunge to the net, and the implications to injury mechanisms. PeerJ, 6(e6033), 13. doi: $10.7717 /$ peerj. 6033

Valldecabres, R., de Benito, A. M., Casal, C. A., \& Pablos, C. (2017). 2015 Badminton world championship: Singles final men's vs. women's behaviours. Journal of Human Sport and Exercise, 12(3proc), 775-788. doi:10.14198/jhse.2017.12.Proc3.01

Vauhnik, R., Morrissey, M. C., Rutherford, O. M., Turk, Z., Pilih, I. A., \& Pohar, M. (2008). Knee anterior laxity: a risk factor for traumatic knee injury among sportswomen? Knee Surgery, Sports Traumatology, Arthroscopy, 16(9), 823833. doi:10.1007/s00167-008-0559-1 
671

\section{Supporting information}

673 S1 Fig. Non-dominant and dominant lunge to the net movement

674 S2 Fig. Net and shuttlecock position during test

675 S3 Fig. Pressure zone distribution and sensor configuration

676 S1 Table. Peak pressure in kilopascals (Kpa) for lead foot

677 S2 Table. 2 Mean pressure in kilopascals (Kpa) for lead foot

678 S3 Table. Peak pressure in kilopascals (Kpa) for trail foot

679 S4 Table. Mean pressure in kilopascals (Kpa) for foot trail foot 
Table 1 Peak pressure in kilopascals (Kpa) for lead foot

\begin{tabular}{|c|c|c|c|c|c|c|c|c|c|}
\hline \multirow[t]{2}{*}{ Parameter } & \multicolumn{2}{|c|}{$\begin{array}{c}\text { LD task } \\
\text { Mean (Kpa) } \pm \text { SD }\end{array}$} & \multicolumn{2}{|c|}{$\begin{array}{c}\text { LND task } \\
\text { Mean }(\text { Kpa }) \pm \text { SD }\end{array}$} & \multirow[t]{2}{*}{$\begin{array}{c}p \text {-value } \\
\text { Interaction }\end{array}$} & \multirow[t]{2}{*}{$\begin{array}{c}p \text {-value } \\
\text { Pre - Post }\end{array}$} & \multirow[t]{2}{*}{$\eta_{p}^{2}$} & \multirow[t]{2}{*}{$\begin{array}{c}p \text {-value } \\
\text { Lunge Dom }\end{array}$} & \multirow[t]{2}{*}{$\eta_{p}^{2}$} \\
\hline & Pre & Post & Pre & Post & & & & & \\
\hline Hallux & $2450.9 \pm 901.6$ & $2520.6 \pm 1127.4$ & $2702.4 \pm 570.4$ & $2315.6 \pm 1117.1$ & 0.170 & 0.460 & 0.05 & 0.913 & 0.00 \\
\hline $2^{\text {nd }} 3^{\text {rd }}$ Phal & $2503.1 \pm 818.5$ & $2257.9 \pm 1328.3$ & $2584.6 \pm 793.7$ & $2269.5 \pm 1150.3$ & 0.731 & 0.284 & 0.10 & 0.716 & 0.01 \\
\hline $4^{\text {th }} 5^{\text {th }} \mathrm{Phal} *$ & $1698.5 \pm 1190.7$ & $851.6 \pm 1022.5$ & $1548.3 \pm 993.5$ & $1206 . \pm 1132.4$ & 0.268 & 0.035 & 0.32 & 0.457 & 0.05 \\
\hline $1^{\text {st }}$ Met & $1887.9 \pm 911.9$ & $1966.7 \pm 1006.0$ & $2209.0 \pm 829.7$ & $2135.30 \pm 841.1$ & 0.475 & 0.991 & 0.000 & 0.058 & 0.27 \\
\hline $2^{\text {nd }} 3^{\text {rd }}$ Mets $t$ & $1616.1 \pm 779.3$ & $1858.1 \pm 919.5$ & $1981.0 \pm 922.8$ & $1435,6 \pm 742.2$ & 0.011 & 0.595 & 0.02 & 0.799 & 0.01 \\
\hline $4^{\text {th }} 5^{\text {th }}$ Mets & $1053.7 \pm 1076.9$ & $1198.1 \pm 1283.7$ & $1261.9 \pm 1028.6$ & $1212.74 \pm 1215.7$ & 0.301 & 0.857 & 0.00 & 0.317 & 0.08 \\
\hline Med-midfoot & $1190.5 \pm 1034.4$ & $1318.5 \pm 1170.2$ & $1058.8 \pm 852.4$ & $1386.3 \pm 944.6$ & 0.569 & 0.393 & 0.06 & 0.796 & 0.01 \\
\hline Lat-midfoot & $1548.9 \pm 1034.9$ & $1423.0 \pm 1159.5$ & $1290.0 \pm 843.5$ & $1660.2 \pm 1295.1$ & 0.146 & 0.618 & 0.02 & 0.893 & 0.00 \\
\hline Calcaneus & $1960.4 \pm 931.5$ & $1770.9 \pm 916.8$ & $2043.9 \pm 797.5$ & $1827.2 \pm 968.6$ & 0.893 & 0.306 & 0.09 & 0.309 & 0.09 \\
\hline
\end{tabular}

* significant difference between Pre and Post $\uparrow$ significant difference between Lunge Dominance \$ significant interaction between Pre and post and Lunge Dominance 
Table 2 Mean pressure in kilopascals (Kpa) for lead foot

\begin{tabular}{|c|c|c|c|c|c|c|c|c|c|}
\hline \multirow[t]{2}{*}{ Parameter } & \multicolumn{2}{|c|}{$\begin{array}{c}\text { LD task } \\
\text { Mean }(\text { Kpa) } \pm \text { SD }\end{array}$} & \multicolumn{2}{|c|}{$\begin{array}{c}\text { LND task } \\
\text { Mean }(\text { Kpa }) \pm \text { SD }\end{array}$} & \multirow{2}{*}{$\begin{array}{c}p \text {-value } \\
\text { Interaction }\end{array}$} & \multirow[t]{2}{*}{$\begin{array}{c}p \text {-value } \\
\text { Pre - Post }\end{array}$} & \multirow[t]{2}{*}{$\eta_{p}^{2}$} & \multirow[t]{2}{*}{$\begin{array}{c}p \text {-value } \\
\text { Lunge Dom }\end{array}$} & \multirow[t]{2}{*}{$\eta_{p}^{2}$} \\
\hline & Pre & Post & Pre & Post & & & & & \\
\hline Hallux & $867.8 \pm 507.2$ & $790.8 \pm 490.5$ & $783.9 \pm 297.1$ & $719.6 \pm 517.1$ & 0.920 & 0.432 & 0.05 & 0.303 & 0.09 \\
\hline $2^{\text {nd }} 3^{\text {rd }}$ Phal & $636.1 \pm 518.1$ & $541.19 \pm 397.2$ & $615.0 \pm 391.25$ & $532.5 \pm 374.6$ & 0.883 & 0.380 & 0.07 & 0.736 & 0.01 \\
\hline $4^{\text {th }} 5^{\text {th }} \mathrm{Phal} *$ & $966.4 \pm 767.5$ & $475.49 \pm 613.9$ & $956.9 \pm 706.13$ & $643.0 \pm 609.1$ & 0.496 & 0.031 & 0.33 & 0.394 & 0.06 \\
\hline $1^{\text {st }}$ Met & $670.8 \pm 350.2$ & $612.53 \pm 355.6$ & $750.2 \pm 381.58$ & $621.3 \pm 310.8$ & 0.354 & 0.331 & 0.08 & 0.374 & 0.07 \\
\hline $2^{\text {nd }} 3^{\text {rd }}$ Mets & $397.2 \pm 206.4$ & $361.56 \pm 193.8$ & $405.5 \pm 159.04$ & $305.8 \pm 168.1$ & 0.220 & 0.176 & 0.15 & 0.459 & 0.05 \\
\hline $4^{\text {th }} 5^{\text {th }}$ Mets & $227.8 \pm 193.1$ & $182.28 \pm 168.7$ & $256.5 \pm 193.29$ & $193.4 \pm 185.3$ & 0.667 & 0.225 & 0.12 & 0.419 & 0.06 \\
\hline Med-midfoot & $298.1 \pm 245.9$ & $317.93 \pm 281.9$ & $258.9 \pm 161.69$ & $320.3 \pm 198.3$ & 0.645 & 0.479 & 0.04 & 0.516 & 0.04 \\
\hline Lat-midfoot & $267.8 \pm 180.2$ & $233.94 \pm 195.3$ & $254.7 \pm 185.42$ & $266.6 \pm 202.5$ & 0.249 & 0.797 & 0.01 & 0.638 & 0.02 \\
\hline Calcaneus $\dagger$ & $635.2 \pm 389.9$ & $538.08 \pm 276.8$ & $661.6 \pm 386.04$ & $596.2 \pm 319.4$ & 0.532 & 0.327 & 0.08 & 0.032 & 0.33 \\
\hline
\end{tabular}

$*$ significant difference between Pre and Post $\uparrow$ significant difference between Lunge Dominance

† significant interaction between Pre and post and Lunge Dominance 
Table 3 Peak pressure in kilopascals (Kpa) for trail foot

\begin{tabular}{|c|c|c|c|c|c|c|c|c|c|}
\hline \multirow[t]{2}{*}{ Parameter } & \multicolumn{2}{|c|}{$\begin{array}{c}\text { LD task } \\
\text { Mean (Kpa) } \pm \text { SD }\end{array}$} & \multicolumn{2}{|c|}{$\begin{array}{c}\text { LND task } \\
\text { Mean }(\text { Kpa }) \pm \text { SD }\end{array}$} & \multirow[t]{2}{*}{$\begin{array}{c}p \text {-value } \\
\text { Interaction }\end{array}$} & \multirow[t]{2}{*}{$\begin{array}{c}p \text {-value } \\
\text { Pre - Post }\end{array}$} & \multirow[t]{2}{*}{$\eta_{p^{2}}$} & \multirow[t]{2}{*}{$\begin{array}{c}p \text {-value } \\
\text { Lunge Dom }\end{array}$} & \multirow[t]{2}{*}{$\eta_{p}^{2}$} \\
\hline & Pre & Post & Pre & Post & & & & & \\
\hline Hallux $1 \dagger$ & $2347.9 \pm 806.9$ & $1984.4 \pm 1161.8$ & $2116.3 \pm 840.5$ & $1619.1 \pm 1052.7$ & 0.671 & 0.083 & 0.23 & 0.008 & 0.45 \\
\hline $2^{\text {nd }} 3^{\text {rd }}$ Phal $\ddagger$ & $1749.7 \pm 965.0$ & $1347.5 \pm 837.0$ & $1250.5 \pm 837.0$ & $1535.8 \pm 1051.3$ & 0.017 & 0.460 & 0.05 & 0.615 & 0.02 \\
\hline $4^{\text {th }} 5^{\text {th }}$ Phal $\uparrow$ & $1040.5 \pm 851.5$ & $764.2 \pm 745.7$ & $673.2 \pm 723.9$ & $492.6 \pm 588.0$ & 0.463 & 0.198 & 0.13 & 0.026 & 0.35 \\
\hline $1^{\text {st }}$ Met $*$ & $2382.0 \pm 915.2$ & $1948.0 \pm 1036.1$ & $2211.8 \pm 1070.1$ & $1870.6 \pm 874.2$ & 0.757 & 0.048 & 0.29 & 0.473 & 0.04 \\
\hline $2^{\text {nd }} 3^{\text {rd }}$ Mets & $1365.3 \pm 993.5$ & $1123.2 \pm 653.8$ & $1413.7 \pm 1034.5$ & $1203.5 \pm 755.8$ & 0.863 & 0.204 & 0.13 & 0.542 & 0.03 \\
\hline $4^{\text {th }} 5^{\text {th }}$ Mets & $1627.2 \pm 1038.0$ & $1265.5 \pm 1082.4$ & $1336.8 \pm 1179.0$ & $1102.1 \pm 986.1$ & 0.575 & 0.084 & 0.23 & 0.106 & 0.20 \\
\hline Med-midfoot * & $576.3 \pm 371.3$ & $967.2 \pm 608.7$ & $595.6 \pm 558.2$ & $998.0 \pm 726.4$ & 0.966 & 0.022 & 0.37 & 0.837 & 0.00 \\
\hline Lat-midfoot & $910.6 \pm 916.8$ & $875.0 \pm 855.3$ & $1146.9 \pm 1220.1$ & $735.1 \pm 692.4$ & 0.191 & 0.288 & 0.09 & 0.702 & 0.01 \\
\hline Calcaneus & $638.4 \pm 415.3$ & $456.1 \pm 279.2$ & $583.5 \pm 332.7$ & $563.4 \pm 376.0$ & 0.095 & 0.167 & 0.15 & 0.659 & 0.02 \\
\hline
\end{tabular}

* significant difference between Pre and Post $\uparrow$ significant difference between Lunge Dominance

\$ significant interaction between Pre and post and Lunge Dominance 
Table 4 Mean pressure in kilopascals (Kpa) for foot trail foot

\begin{tabular}{|c|c|c|c|c|c|c|c|c|c|}
\hline \multirow[t]{2}{*}{ Parameter } & \multicolumn{2}{|c|}{$\begin{array}{c}\text { LD task } \\
\text { Mean (Kpa) } \pm \text { SD }\end{array}$} & \multicolumn{2}{|c|}{$\begin{array}{c}\text { LND task } \\
\text { Mean }(\text { Kpa }) \pm \text { SD }\end{array}$} & \multirow{2}{*}{$\begin{array}{c}p \text {-value } \\
\text { Interaction }\end{array}$} & \multirow{2}{*}{$\begin{array}{c}p \text {-value } \\
\text { Pre - Post }\end{array}$} & \multirow[t]{2}{*}{$\eta_{p}^{2}$} & \multirow{2}{*}{$\begin{array}{c}p \text {-value } \\
\text { Lunge Dom }\end{array}$} & \multirow[t]{2}{*}{$\eta_{p}^{2}$} \\
\hline & Pre & Post & Pre & Post & & & & & \\
\hline Hallux $* \dagger$ & $649.8 \pm 318.4$ & $488.5 \pm 302.2$ & $560.85 \pm 245.9$ & $425.06 \pm 329.0$ & 0.811 & 0.020 & 0.38 & 0.038 & 0.31 \\
\hline $2^{\text {nd }} 3^{\text {rd }}$ Phal & $336.8 \pm 219.9$ & $221.7 \pm 159.3$ & $291.76 \pm 239.0$ & $254.67 \pm 190.2$ & 0.101 & 0.067 & 0.25 & 0.806 & 0.01 \\
\hline $4^{\text {th }} 5^{\text {th }}$ Phal $\dagger$ & $564.6 \pm 453.3$ & $408.7 \pm 383.6$ & $376.04 \pm 395.08$ & $280.43 \pm 312.5$ & 0.349 & 0.175 & 0.15 & 0.017 & 0.39 \\
\hline $1^{\text {st }}$ Meta * & $804.1 \pm 439.2$ & $645.1 \pm 501.3$ & $721.71 \pm 353.45$ & $576.00 \pm 286.0$ & 0.869 & 0.046 & 0.29 & 0.312 & 0.09 \\
\hline $2^{\text {nd }} 3^{\text {rd }}$ Meta & $354.8 \pm 233.7$ & $284.2 \pm 161.2$ & $406.64 \pm 240.6$ & $323.44 \pm 172.7$ & 0.711 & 0.113 & 0.20 & 0.120 & 0.19 \\
\hline $4^{\text {th }} 5^{\text {th }}$ Meta & $300.9 \pm 192.7$ & $271.3 \pm 264.2$ & $246.46 \pm 163.32$ & $223.26 \pm 198.4$ & 0.791 & 0.449 & 0.05 & 0.130 & 0.18 \\
\hline Med-midfoot $*$ & $155.3 \pm 79.8$ & $225.7 \pm 122.5$ & $138.82 \pm 103.71$ & $216.72 \pm 147.7$ & 0.889 & 0.046 & 0.29 & 0.623 & 0.02 \\
\hline Lat-midfoot & $174.5 \pm 135.5$ & $162.9 \pm 146.5$ & $195.1 \pm 170.17$ & $128.49 \pm 114.1$ & 0.138 & 0.177 & 0.15 & 0.619 & 0.02 \\
\hline Calcaneus & $229.0 \pm 139.1$ & $208.0 \pm 154.1$ & $236.27 \pm 150.6$ & $237.8 \pm 182.8$ & 0.378 & 0.813 & 0.01 & 0.372 & 0.07 \\
\hline
\end{tabular}

* significant difference between Pre and Post $\uparrow$ significant difference between Lunge Dominance

\$ Significant interaction between Pre and post and Lunge Dominance 


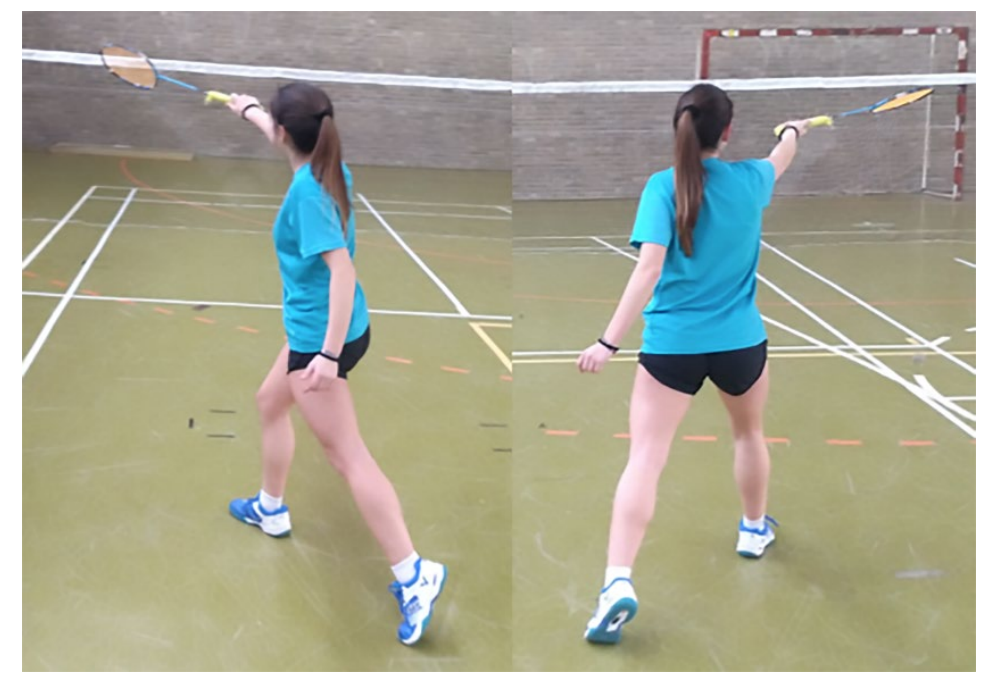

Figure 1. Non-dominant and dominant lunge to the net movement 


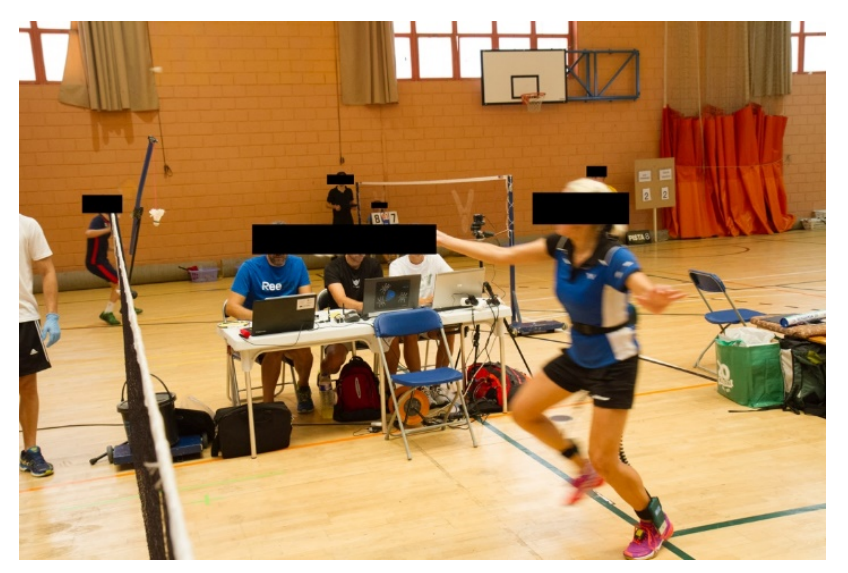

Figure 2. Net and shuttlecock position during test 


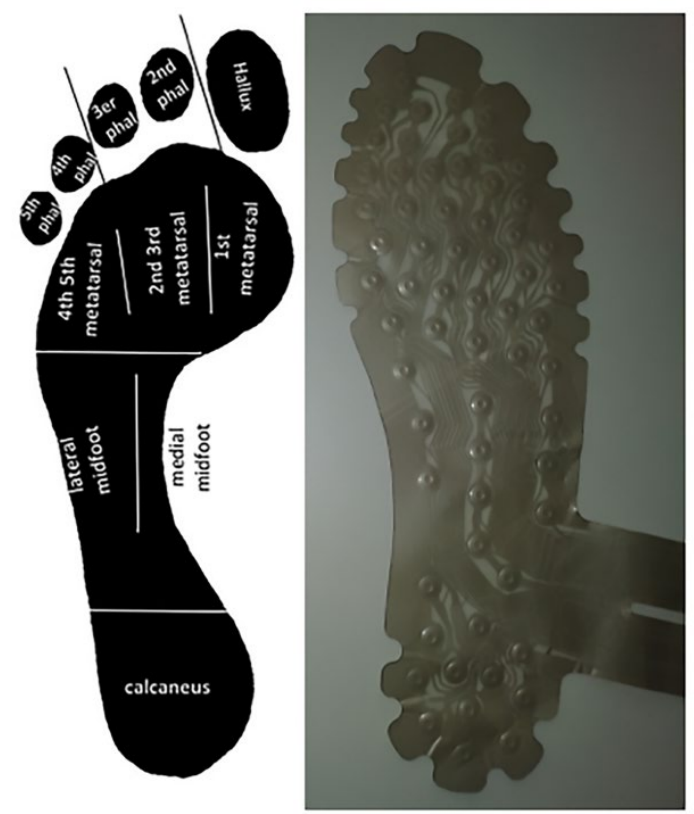

Figure 3. Pressure zone distribution and sensor configuration 